\title{
Survival and Growth of American Alligator (Alligator mississippiensis) Hatchlings after Artificial Incubation and Repatriation
}

\author{
Yosapong Temsiripong, ${ }^{1,2}$ Allan R. Woodward, ${ }^{3,4}$ James P. Ross, ${ }^{5,6}$ Paul S. Kubilis, ${ }^{3}$ \\ AND H. FRANKLIN Percival ${ }^{7}$ \\ ${ }^{1}$ Department of Wildlife Ecology and Conservation, 110 Newins-Ziegler Hall, University of Florida, \\ Gainesville, Florida 32611, USA \\ ${ }^{3}$ Florida Fish and Wildife Conservation Commission, 4005 South Main Street, Gainesville, Florida 32601, USA \\ ${ }^{5}$ Florida Museum of Natural History, Dickinson Hall, University of Florida, Gainesville, Florida 32611, USA \\ ${ }^{7}$ Cooperative Fish and Wildife Research Unit, U.S. Geological Survey, University of Florida, Gainesville, \\ Florida 32611, USA
}

\begin{abstract}
Aвstract.-Hatchling American Alligators (Alligator mississippiensis) produced from artificially incubated wild eggs were returned to their natal areas (repatriated). We compared artificially incubated and repatriated hatchlings released within and outside the maternal alligator's home range with naturally incubated hatchlings captured and released within the maternal alligator's home range on Lake Apopka, Lake Griffin, and Orange Lake in Florida. We used probability of recapture and total length at approximately nine months after hatching as indices of survival and growth rates. Artificially incubated hatchlings released outside of the maternal alligator's home range had lower recapture probabilities than either naturally incubated hatchlings or artificially incubated hatchlings released near the original nest site. Recapture probabilities of other treatments did not differ significantly. Artificially incubated hatchlings were approximately $6 \%$ shorter than naturally incubated hatchlings at approximately nine months after hatching. We concluded that repatriation of hatchlings probably would not have long-term effects on populations because of the resiliency of alligator populations to alterations of early age-class survival and growth rates of the magnitude that we observed. Repatriation of hatchlings may be an economical alternative to repatriation of older juveniles for population restoration. However, the location of release may affect subsequent survival and growth.
\end{abstract}

Crocodilians are one of the few reptiles to exercise maternal care of young (Ferguson, 1985). Female American Alligators (Alligator mississippiensis) typically attend their nests (Joanen, 1969; Deitz and Hines, 1980; Kushlan and Kushlan, 1980), aid in the hatching process (Joanen, 1969; Deitz and Hines, 1980; Kushlan and Simon, 1981), and retain a close association with the young during at least the first nine months after hatching (Deitz, 1979; Woodward et al., 1987). Posthatching maternal protection is thought to enhance survival of young (Deitz, 1979). Nest and nursery site location also may contribute to survival and growth of young alligators by providing them with favorable habitat (Deitz, 1979).

\footnotetext{
${ }^{2}$ Present address: Crocodile Management Association of Thailand, 383 M 4 Nongkham Sriracha, Chonburi 20110; E-mail: yosapong@srirachamoda. com

${ }^{4}$ Corresponding Author. E-mail: allan.woodward@ myfwc.com

${ }^{6}$ Present Address: Department of Wildlife Ecology and Conservation, Newins-Ziegler Hall, University of Florida, Gainesville, Florida 32611, USA.
}

Alligator eggs have been collected from the wild in Florida and artificially incubated, and the resulting hatchlings have been returned to their area of origin (repatriated) as part of studies examining clutch viability (Woodward et al., 1993) and factors affecting embryonic development (Guillette et al., 1994). An important component of these studies has been to evaluate the effect of clutch viability on population growth. In Louisiana, juvenile (90$121 \mathrm{~cm}$ ) alligators, hatched and reared in captivity then repatriated to compensate for egg removals, appear to survive and grow as well as wild alligators (Addison, 1993; Bossert, 1993; Elsey et al., 1998). However, no assessment has been made of survival and growth of alligators repatriated as hatchlings. Hatchlings have not been considered for repatriation because of higher mortality rates relative to older alligators and the possibility of even higher mortality if dissociated from the maternal alligator. To better understand effects of repatriation, we examined survival and growth indices of artificially incubated and released hatchlings relative to hatchlings that incubated and hatched in the wild. 


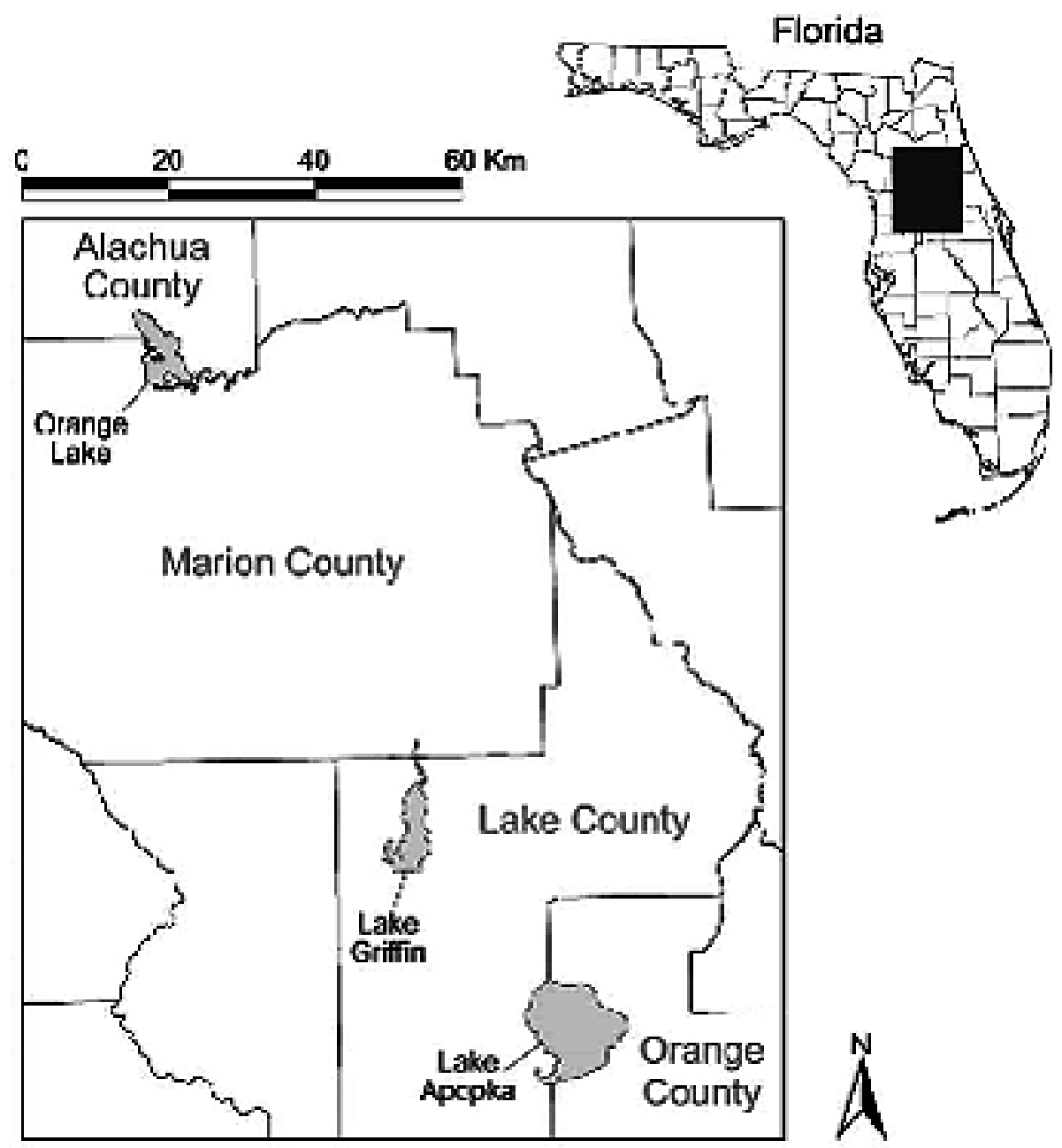

FIG. 1. Study areas, Lake Apopka, Lake Griffin, and Orange Lake, in central Florida, where hatchling alligators were repatriated.

We hypothesized that repatriated hatchlings would have altered survival and growth rates relative to hatchlings from naturally incubated eggs. Further, we hypothesized that repatriated hatchlings released near the nest site would have different survival and growth rates than hatchlings released in suitable habitat away from the nest site. We tested these hypotheses by comparing relative recapture probabilities and total length (TL) at nine months after hatching as indices of hatchling survival and growth rates.

\section{Materials AND Methods}

We collected clutches of alligator eggs during summer 1998 from marshes and swamps associated with Lake Apopka, Lake Griffin, and Orange Lake in north-central Florida
(Fig. 1). We recorded longitude and latitude at nest sites using a Global Positioning System (GPS) receiver, which was subsequently used to assist navigation when returning to release and recapture hatchlings. Clutches were artificially incubated at $32^{\circ} \mathrm{C}$ in an insulated incubation shed as described by Woodward et al. (1993). All eggs within a clutch were incubated together in an individual container that prevented mixing of eggs or neonates with other clutches All hatchlings from an individual clutch were siblings (same mother), and we refer to groups of sibling hatchlings as "pods." After hatching, neonates were transferred to tanks, maintaining the integrity of pods, and held at $30-32^{\circ} \mathrm{C}$ for $2-4$ weeks before being released. They were fed a commercially processed alligator food (Burris Mill and Feed, Inc., Franklinton, LA) beginning at day 7 after hatch 
and continuing three days per week until they were released. Each hatchling was tagged on the web of the right-rear foot with an individually numbered, size 1 Monel tag (National Band and Tag Co., Newport, KY). Initial total length $\left(\mathrm{TL}_{0}\right)$ was obtained for each alligator two days prior to release.

We repatriated pods near the original nest site or outside the maternal alligator's home range. We considered habitat outside maternal home range as suitable if it had shallow water with emergent vegetation and had been occupied by hatchlings in previous years (Deitz, 1979; Woodward et al., 1987). We chose release sites that had no active nests in 1998 to minimize the chance of interaction with active maternal alligators or their pods. All release sites outside the maternal home range were $>1 \mathrm{~km}$ from the original nest site. The maximum home-range radius of adult females during the nesting season was $<0.35 \mathrm{~km}$ in Louisiana marshes (Joanen and McNease, 1970) and estimated to be $<0.32 \mathrm{~km}$ on a north-central Florida lake (Goodwin and Marion, 1979). Therefore, we considered that a $1.0 \mathrm{~km}$ distance from the release site was sufficient to separate the pod from both the potential influence of the maternal alligator and the microhabitat of the original nest site. Hatchlings repatriated within the maternal home range were released either in the nest guard pool or at the junction of the nearest permanent water and the primary trail from the nest. Naturally incubated and hatched alligators were located and captured by hand or with Pillstrom tongs (Pillstrom Tong Co., Ft. Smith, AR) at night during 3 September to 17 November 1998. These were marked and measured similarly to hatchlings from artificially incubated eggs and immediately released.

We conducted periodic observations of pods after releasing them to facilitate recapture. We attempted to recapture pods during May to July 1999 by searching at the original nest site or at the last site where they were observed. Pod searches were conducted systematically by section of lake rather than by treatment. This yielded a similar average recapture date for all treatments within a lake. In cases where a pod could not be found on the first search attempt, subsequent attempts were made on different nights. If we did not find any member of a pod after several search attempts, the pod was considered lost (dead, unable to be caught, or moved). Upon finding pods, we attempted to recapture all individuals on a single night until no additional hatchlings could be found or caught. We applied the same protocol to pods in all treatment groups and on all lakes. We recorded the tag number and total length at time of recapture $\left(\mathrm{TL}_{1}\right)$ for all hatchlings.
We carried out a statistical analysis to assess the influence of experimental treatment and lake of origin (Apopka, Griffin, Orange) on two outcome variables: the probability that a hatchling would be recaptured at or near the release site approximately nine months (275 days) after release, and $\mathrm{TL}_{1}$. The three treatments consisted of naturally incubated hatchlings released within the nesting season maternal home range (NIWHR), artificially incubated hatchlings released within the nesting season maternal home range (AI-WHR), and artificially incubated hatchlings released outside the nesting season maternal home range (AI-OHR). Table 1 shows the distribution of pods within each lake-treatment cell.

Survival Rates.-We used probability of recapture resulting from a single rigorous and operationally-defined recapture effort as an index of hatchling survival. In analyzing the probability of single-effort recapture, we assumed that this probability depended on the length of the release-recapture time interval and also on the rate at which hatchlings became unavailable for recapture. Because the length of the release-recapture time interval differed among pods by as much as 111 days (range: 199-310 days, median: 273.5 days), hatchling recapture probabilities estimated as the simple proportion of hatchlings recaptured from each pod were confounded by time and could not be compared directly among treatment groups and study sites. Therefore, we adopted the conceptual framework of survival analysis (Kalbfleisch and Prentice, 1980; Cox and Oakes, 1984) to estimate a pod-specific hatchling recapture index, which did not depend on the length of the release-recapture interval and, thus, could be compared fairly among treatment groups. In survival analysis, it is assumed that the probability of survival beyond time $t$ is predicted by a survivor function, the mathematical form of which is determined by the probability distribution assumed for loss or failure time $t$. The probability distribution of $t$ also determines the form of the hazard function, or time-specific loss rate. We assumed that hatchling loss times followed an exponential probability distribution and, thus, assumed that the recapture probability for an alligator hatchling at time $t$ after release is predicted by the survivor function $e^{-\lambda t}$. Correspondingly, the time-specific loss rate at time $t$ is predicted by the hazard function $\lambda$ (Cox and Oakes, 1984). By assuming exponentially distributed loss times, we assumed that the hatchling hazard rate remained constant over time. The percent loss of hatchlings to recapture in such a released population would, thus, be expected to remain constant within arbitrarily sized sequential time intervals of 
TABLE 1. Back-transformed (BT) mean probability of recapture (Pr Recapture) and BT-mean total length at nine months after release $\left(\mathrm{TL}_{1}\right)$ of artificially incubated and repatriated alligator hatchlings and naturally incubated alligator hatchlings on lakes Apopka, Griffin, and Orange, Florida during 1998-1999. Sample size (N) represents the number of pods contributing to probability of recapture and total length estimates.

\begin{tabular}{|c|c|c|c|c|c|c|c|}
\hline \multirow[b]{2}{*}{ Lake } & \multirow[b]{2}{*}{ Treatment group ${ }^{a}$} & \multicolumn{3}{|c|}{ BT Pr Recapture } & \multicolumn{3}{|c|}{ BT TL $\mathrm{TL}_{1}(\mathrm{~cm})$} \\
\hline & & N & Mean & $95 \%$ CI & N & Mean & $95 \%$ CI \\
\hline \multirow{3}{*}{ All lakes } & NI-WHR & 22 & 0.23 & $\left(\begin{array}{lll}0.17 & 0.29\end{array}\right)$ & 22 & 45.1 & (43.3 46.9) \\
\hline & AI-WHR & 34 & 0.22 & $\left(\begin{array}{lll}0.18 & 0.27\end{array}\right)$ & 31 & $42.3^{\mathrm{b}}$ & $(40.643 .9)$ \\
\hline & AI-OHR & 14 & $0.15^{\mathrm{bc}}$ & $\left(\begin{array}{lll}0.10 & 0.21\end{array}\right)$ & 14 & 42.2 & (38.8 45.8) \\
\hline Lake & NI-WHR & 8 & 0.23 & $\left(\begin{array}{lll}0.15 & 0.33)\end{array}\right.$ & 8 & 40.3 & (37.0 43.9) \\
\hline \multirow[t]{2}{*}{ Apopka } & AI-WHR & 10 & 0.26 & $\left(\begin{array}{lll}0.19 & 0.34\end{array}\right)$ & 10 & 39.9 & (36.9 43.0) \\
\hline & AI-OHR & 5 & 0.18 & $\left(\begin{array}{lll}0.09 & 0.29\end{array}\right)$ & 5 & 35.9 & (29.7 43.5) \\
\hline Lake & NI-WHR & 8 & 0.26 & (0.17 0.36$)$ & 8 & 45.5 & (42.9 48.3) \\
\hline \multirow{2}{*}{ Griffin } & AI-WHR & 5 & 0.16 & $\left(\begin{array}{lll}0.09 & 0.26\end{array}\right.$ & 5 & 41.7 & (38.6 45.0) \\
\hline & AI-OHR & 5 & $0.12^{\mathrm{b}}$ & $\left(\begin{array}{lll}0.05 & 0.20\end{array}\right)$ & 5 & 43.1 & (39.4 47.1) \\
\hline Orange & NI-WHR & 6 & 0.20 & $\left(\begin{array}{lll}0.10 & 0.32\end{array}\right)$ & 6 & 49.8 & $(46.952 .9)$ \\
\hline \multirow[t]{2}{*}{ Lake } & AI-WHR & 19 & 0.24 & (0.19 0.30$)$ & 16 & $45.4^{\mathrm{b}}$ & (43.5 47.4) \\
\hline & AI-OHR & 4 & 0.15 & $\left(\begin{array}{lll}0.06 & 0.27)\end{array}\right.$ & 4 & 48.4 & (42.7 54.8) \\
\hline
\end{tabular}

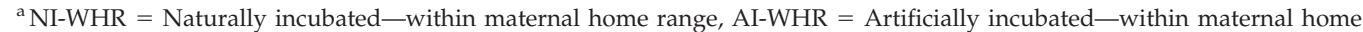
range, $\mathrm{AI}-\mathrm{OHR}=$ Artificially incubated-outside maternal home range.

${ }^{\mathrm{b}}$ Different $(P<0.1)$ from NI-WHR in pairwise comparisons within lake category.

${ }^{c}$ Different $(P<0.1)$ from AI-WHR in pairwise comparisons within lake category.

equal length. Although it is possible that the hatchling hazard rate may have varied over the release-recapture time interval, we considered the assumption of a constant hazard rate as reasonable and parsimonious in the absence of any data (i.e., exactly determined loss times) to suggest a more appropriate probability distribution or hazard function for loss times.

We used parametric exponential survival regression (Kalbfleich and Prentice, 1980) as implemented in PROC LIFEREG (SAS/STAT Software, Vers. 8.1) to estimate the log-hazard rate and its variance for each pod of hatchlings observed during the study. To estimate the pod log-hazard rate for three pods released on Orange Lake from which no hatchlings were recovered, we assumed that the last hatchling lost to recapture in each pod was lost immediately prior to the start of respective recapture efforts targeting these pods.

We next used the pod log-hazard rates as response observations in a two-way analysis of variance (ANOVA) to model experimental treatment and lake of origin as completely crossed fixed factors each having three levels. To account for variation in the precision of the pod log-hazard rate estimates that resulted from differences in the number of hatchlings per pod (range: 8-41) and differences among pods in the release-recapture time interval, a weighted residual sum of squares was minimized in the ANOVA (Box et al., 1978). The weight for each squared residual was the reciprocal of the variance of the corresponding pod log-hazard rate. Besides appropriately giving more weight to more precisely estimated responses, the weighting ensured that the weighted leastsquares estimates of treatment means, effects, and corresponding standard errors would be best linear unbiased estimators (BLUE; Seber, 1977). Within the ANOVA, we used an F-test to test for a significant interaction before evaluating significance of treatment and lake main effects and simple treatment main effects (i.e., the treatment main effect within each lake). We evaluated significance of pairwise differences among main effect treatment means and among treatment means within each lake by considering the ratio of each difference to its ANOVAestimated standard error as a $t$-statistic (equivalent to performing the Fisher LSD test). No attempt was made to adjust $t$-statistic $P$-values for multiple comparisons among treatment means, since these comparisons were considered of interest a priori. Box-Cox analysis (Box and Cox, 1964) and normal probability plots of residuals (Tukey, 1977) were used to confirm the appropriateness of the log-scale on which the pod hazard rates were analyzed. To make the ANOVA results more accessible, we used the survivor function for exponentially distributed loss times and the treatment group mean log-hazard rates and corresponding 95\% confidence intervals to estimate treatment group probabilities of recapturing a hatchling at or near the release site 275 days (nine months) after being released.

Growth Rates.-We used total length of hatchlings at time of recapture $\left(\mathrm{TL}_{1}\right)$ as an index of growth rate. In analyzing $\mathrm{TL}_{1}$, we assumed that hatchling growth prior to recapture occurred in two phases (fall and spring) separated 
by a winter no-growth phase induced by cooler winter temperatures (Deitz, 1979; Coulson and Hernandez, 1983; A. R. Woodward, C. T. Moore, and M. F. Delany, unpubl. data). We also assumed that the end of the fall growth phase and the start of the spring growth phase occurred at approximately the same time on each of the three lakes used in the study. Because we could not determine exact hatching dates for naturally incubated hatchlings, we assumed that the range and distribution of hatching dates in this treatment group were similar to those of both artificially incubated treatment groups, where hatching dates spanned a 30-day interval. We assumed that the spring growth phase started at the same time for all hatchlings. Consequently, duration of the spring growth phase until recapture was determined by the date of the recapture effort that targeted each pod. Because the earliest and latest recapture efforts occurred on 25 May 1999 and 3 July 1999, we assumed the range of individual hatchling spring growth phase intervals to be 40 days and used the relative difference in length of the spring growth phase (0-39 days relative to the earliest recapture effort) as a covariate in our analysis of $\mathrm{TL}_{1}$. We performed a conditional two-way ANOVA (Littell et al., 1996) on the $\log$ of $\mathrm{TL}_{1}$, with experimental treatment and lake of origin considered as completely crossed fixed factors each having three levels and relative difference in length of the spring growth phase modeled as a linear covariate plus additional terms, which allowed this covariate to interact completely with treatment and lake interaction and main effects. Pod was modeled as a random effect nested within the completely crossed main effects. After using PROC MIXED (SAS/STAT Software, Vers. 8; Littell et al., 1996) to fit this model, conditional least-squares estimates of treatment means, effects, and corresponding standard errors were generated with the relative difference in length of the spring growth phase set to the midpoint of its range, which corresponded to a recapture date of 15 June 1999. These conditional estimates were considered free of the confounding linear influence on $\mathrm{TL}_{1}$ introduced by variation in the date of recapture efforts. All further analysis of conditional treatment and lake interaction and main effects and comparison of conditional treatment group means was performed as described for the analysis of recapture probabilities. Box-Cox analysis (Box and Cox, 1964) and normal probability plots of residuals (Tukey, 1977) were again used to confirm the appropriateness of the log-scale on which $\mathrm{TL}_{1}$ was analyzed. For ease of use, we transformed conditional means and $95 \%$ confidence intervals estimated on the log-scale back to original units of $\mathrm{TL}_{1}$ for each treatment group. For all statistical tests, we considered $P<0.10$ to be biologically significant.

\section{Results}

We repatriated 34 pods within the maternal home range and 14 pods outside the maternal home range, and we captured and released hatchlings from 22 naturally incubated pods (Table 1). Pod sizes for all treatment groups ranged from 8-41 hatchlings per pod. We recaptured 347 hatchlings from 67 pods. We were unable to recapture any hatchlings in three pods repatriated within the maternal home range on Orange Lake (Table 1).

Probability of Recapturing Hatchlings.-In analyzing recapture probabilities, we found no significant interaction $\left(F_{4,61}=0.81, P=0.521\right)$ between lake and experimental treatment effects. Thus, the pattern of response difference among treatment groups did not depend appreciably on lake. We, then, examined the treatment and lake main effects. Mean treatment group recapture probabilities did not differ significantly $\left(F_{2,61}=0.77, P=0.469\right)$ among lakes (Fig. 2). Recapture probabilities differed $\left(F_{2,61}=2.54, P=0.087\right)$ among treatment groups (Fig. 2). Pairwise comparisons of treatment groups indicated that the mean capture probability of the AI-OHR group was less than the NI-WHR $\left(t_{61}=-2.03, P=0.046\right)$ or AI-WHR $\left(t_{61}=-2.03, P=0.047\right)$ groups (Table 1). Capture probabilities of the NI-WHR and AI-WHR groups did not differ significantly from one another $\left(t_{61}=-0.26, P=0.793\right.$; Table1).

Total Length of Hatchlings.-In analyzing $\mathrm{TL}_{1}$, we found no significant interaction $\left(F_{4,50}=0.71\right.$, $P=0.591)$ between lake and experimental treatment effects, indicating that differences in $\mathrm{TL}_{1}$ among treatment groups did not depend on study areas. Therefore, we examined treatment and lake main effects. We did find evidence of differences in estimated mean $\mathrm{TL}_{1}$ both among lakes $\left(F_{2,50}=12.35, P<0.001\right)$ and among treatment groups $\left(F_{2,50}=2.97, P=0.060\right.$; Fig. 3$)$. Estimated $\mathrm{TL}_{1}$ differed $\left(t_{50}<-2.70, P<0.01\right)$ among all lakes with the main effect, mean $\mathrm{TL}_{1}$, greatest for Orange Lake $(48.0 \mathrm{~cm})$, intermediate for Lake Griffin $(43.4 \mathrm{~cm})$, and least for Lake Apopka (38.7 cm; Fig. 3).

Pairwise comparison of the treatment groups indicated that mean $\mathrm{TL}_{1}$ averaged across lakes was greater in the NI-WHR group when compared to the AI-WHR group $\left(t_{50}=2.31, P\right.$ $=0.025$; Table 1, Fig. 3). Mean estimated $\mathrm{TL}_{1}$ for the AI-OHR group did not differ significantly from either the NI-WHR group mean $\left(t_{50}=\right.$ 


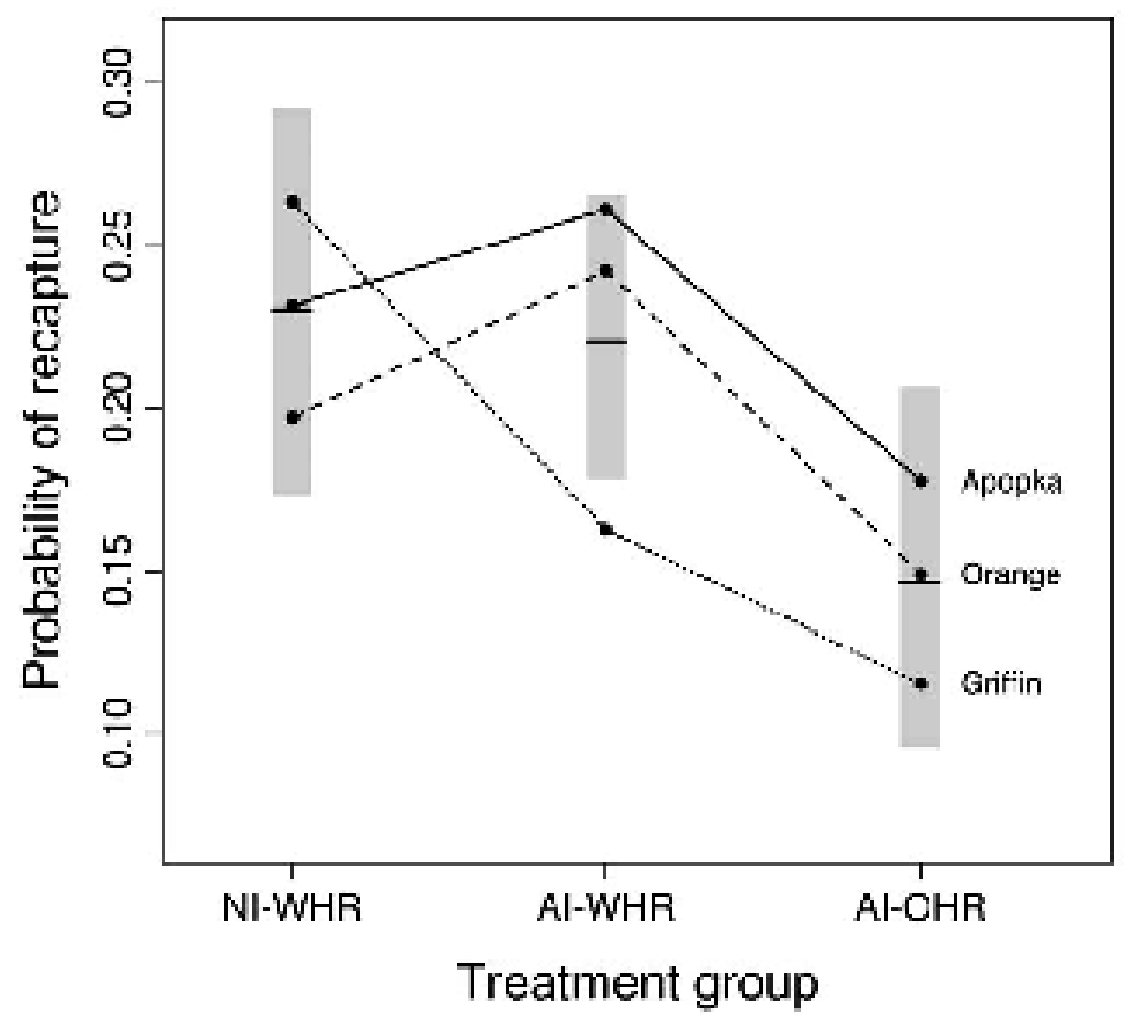

FIG. 2. Mean probability of recapture at approximately nine months after hatching for alligator hatchlings released on lakes Apopka, Griffin, and Orange in Florida during 1998-1999. Treatment group pods were naturally incubated and released within maternal home ranges (NI-WHR), artificially incubated and released within maternal home ranges (AI-WHR), or artificially incubated and released outside maternal home ranges (AI-OHR). Vertical bars represent treatment group main effect means and 95\% confidence bounds.

$1.47, P=0.149)$ or the AI-WHR group mean $\left(t_{50}\right.$ $=0.05, P=0.959$; Table 1 ).

Mean $\mathrm{TL}_{1}$ among treatment groups did not differ significantly for Lake Apopka $\left(F_{2,50}=\right.$ $0.61, P=0.547)$ and Lake Griffin $\left(F_{2,50}=1.78, P\right.$ $=0.179 ;$ Table 1 , Fig. 3$)$. Mean $\mathrm{TL}_{1}$ differed among treatment groups on Orange Lake $\left(F_{2,50}\right.$ $=3.27, P=0.046)$ with the NI-WHR mean being greater than the AI-WHR mean $\left(t_{50}=2.51, P=\right.$ 0.016; Table 1). All other pairwise comparisons of treatment groups within lakes were nonsignificant $\left(t_{50}<0.42, P>0.1\right.$; Table 1$)$.

\section{DisCUSSION}

The primary purpose of this experiment was to evaluate whether artificially incubated alligator hatchlings would have different survival and growth rates after repatriation compared with hatchlings incubated under natural conditions. We used recapture rates as an index of survival rates and total length at nine months as an index of growth rate for comparing differences among treatments in our experiment.
Although recapture rates should not be viewed as estimates of actual survival rates, they can provide a useful indicator of relative survival rates. Estimated recapture rates indicated that survival rates did not differ substantially between naturally incubated alligator hatchlings and repatriated hatchlings released near their nest site. Artificially incubated hatchlings released outside the maternal home range had lower survival rates than artificially incubated hatchlings released at or near the nest site. Therefore, releasing repatriated hatchlings at or near the nest site could improve their survival chances. Lower survival rates of hatchlings repatriated outside of the maternal home range may be caused by increased mortality resulting from lack of maternal care or to selection of suboptimum habitat by the researchers. There was no evidence to suggest artificially incubated pods, released outside the maternal home range, were more prone to fragmentation or dispersal than the other groups.

Repatriated hatchlings grew $6 \%$ slower on average than naturally incubated hatchlings 


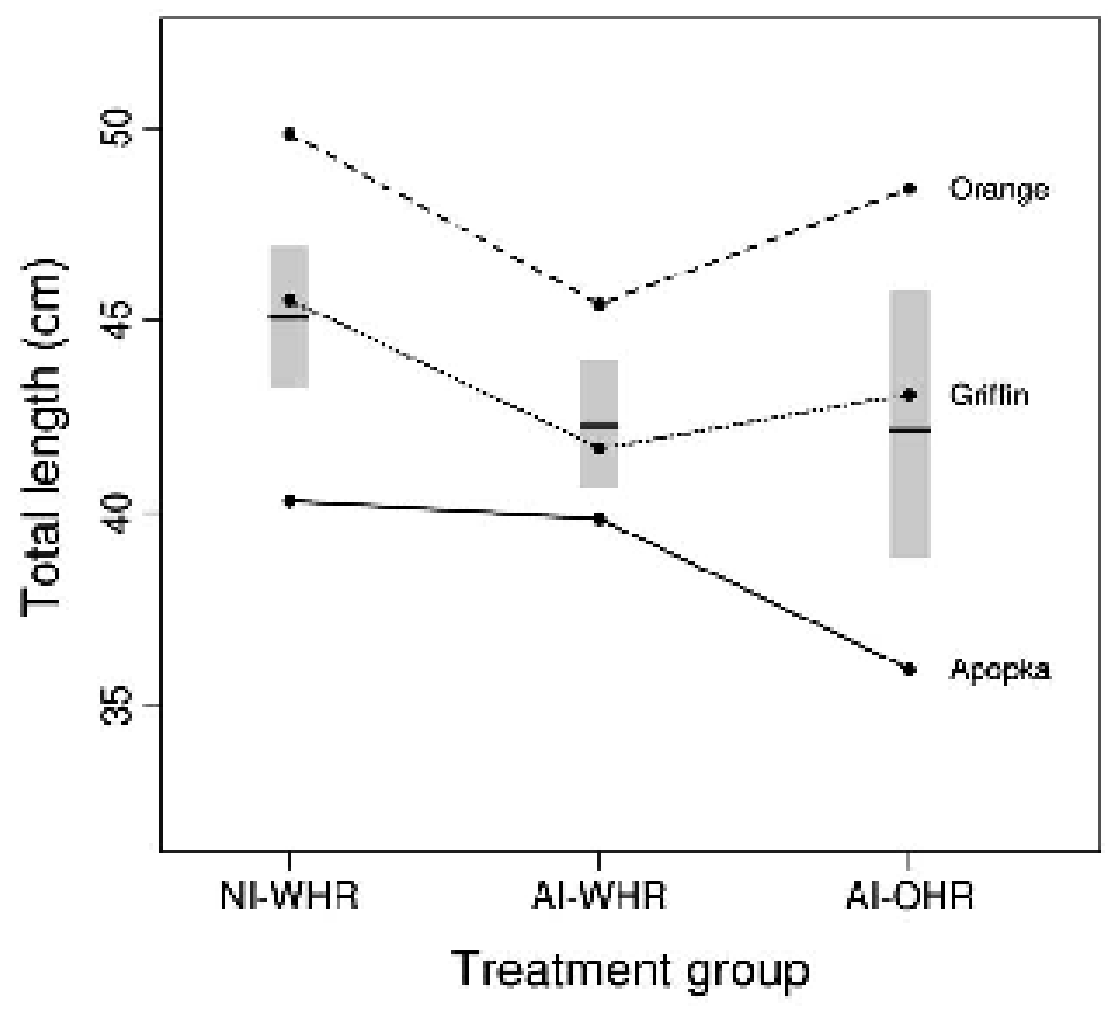

FIG. 3. Mean total length at approximately 9 months after hatching for alligator hatchlings released on lakes Apopka, Griffin, and Orange in Florida during 1998-1999. Treatment group pods were naturally incubated and released within maternal home ranges (NI-WHR), artificially incubated and released within maternal home ranges (AI-WHR), or artificially incubated and released outside maternal home ranges (AI-OHR). Vertical bars represent treatment group main effect means and 95\% confidence bounds.

regardless of placement with respect to maternal home ranges, but only those repatriated within the maternal home range grew significantly slower. We observed high variability in total length of hatchlings repatriated outside the maternal home range, which contributed to the uncertainty of our inferences about relative growth rates.

Although we were primarily concerned with the effects of diminished survival rates, increased survival rates can also be a problem if the goal is to maintain natural population growth, as it was on our research areas. Collection of eggs from the wild during early incubation can preclude losses resulting from predation and flooding. Therefore, return of all hatchlings produced from artificially incubated eggs will usually increase the recruitment rate of hatchlings above natural levels. If the objective is to maintain natural recruitment rates, and survival rates of repatriated hatchlings are not different from those of naturally incubated hatchlings, only a portion of hatchlings from artificially incubated eggs should be repatriated, and that portion should be dependent on area-specific natural nest loss rates.

Why hatchlings repatriated near their original nest site survived as well on average as naturally incubated hatchlings is uncertain. However, we frequently observed alligators of adult female size in association with pods repatriated within the maternal home range (Temsiripong, 1999). These adults behaved similarly to adults associated with naturally incubated pods, suggesting that some maternal females may reconnect with repatriated pods and provide some maternal care. This seems plausible because females typically remain in the vicinity of the nest throughout the incubation period (Joanen and McNease, 1970; Goodwin and Marion, 1979; Taylor, 1984) and open nests to release the young upon hatching (Deitz and Hines, 1980).

A broader question to consider was whether repatriation would affect the long-term growth of alligator populations. Alligator populations appear very resilient to alterations in early ageclass survival rates. This has been demonstrated 
under natural conditions, experimental manipulations, and computer simulations. Annual loss of alligator nests to predation or flooding can vary from $11-95 \%$ for a given area and year in Florida (Deitz and Hines, 1980; Jennings et al., 1988; Kushlan and Jacobsen, 1990). Field experiments also indicate that recruitment rates of hatchling alligators can be substantially reduced by egg and hatchling collection without significantly affecting population growth (Rice et al., 1999). Population modeling simulations suggest that differences in survival rate indices of the magnitude that we observed $(0.23-0.15$ / yr) should have little effect on alligator population growth (K. G. Rice and H. F. Percival, unpubl. data). The long-term effect of the approximately $6 \%$ slower growth rates of repatriated hatchlings during the first nine months on population growth is unknown. Some evidence suggests that early developmental conditions may influence future growth rates of alligators under controlled captive conditions (Joanen et al., 1987). However, we suspect that differences in growth of the magnitude that we observed in this study would eventually be obscured by environmental and population density influences.

Although the primary purpose of this study was to determine whether artificially incubating alligator eggs and repatriating the resulting hatchlings would significantly alter hatchling alligator survival and growth rates, our findings may have broader applicability. Artificial incubation of eggs and repatriation of hatchlings may be a viable option for enhancing hatchling recruitment rates of alligators and other crocodilians where nests are subject to high predation or flooding rates. This may be particularly applicable in situations where juvenile rearing facilities are unavailable or cost prohibitive or where the cost of raising juveniles to larger sizes is uneconomical.

Acknowledgments.-We are grateful to D. Carbonneau, A. Brunell, J. White, and C. Visscher, for assistance with hatchling repatriation and data collection. Special thanks go to F. W. King and R. R. Carthy for providing guidance on study design and for reviewing earlier versions. We also thank H. Dutton, S. Linda, T. O'Meara, and J. D. Nichols for reviewing the earlier drafts of this manuscript and R. Kiltie, P. Moler, and K. Rice for reviewing the final draft. This study was financially and technically supported by the Florida Fish and Wildlife Conservation Commission, the Florida Museum of Natural History, and the Florida Cooperative Fish and Wildlife Research Unit, USGS-BRD. This paper represents Florida Experimental Station Journal
Series R-08597. Alligators were handled and maintained in accordance with ASIH-HL-SSAR guidelines for use of live reptiles, as well as Florida Fish and Wildlife Conservation Commission rules and regulations governing the care and housing of captive crocodilians.

\section{Literature Cited}

Addison, B. G. 1993. Survival and Movement of FarmRaised Alligators Released in a Freshwater Marsh in Southeastern Louisiana. Unpubl. master's thesis, Louisiana State University, Baton Rouge.

Bossert, D. C. 1993. Comparison of Growth Rates of Immature Farm-Raised Alligators Released into the Wild and Immature Wild Alligators. Unpubl. master's thesis, Louisiana State University, Baton Rouge.

Box, G. E. P., AND D. R. Cox. 1964. An analysis of transformations. Journal of the Royal Statistical Society, Series B 26:211.

Box, G. E. P., W. G. Hunter, and J. S. Hunter. 1978. Statistics for Experimenters. John Wiley and Sons, Inc., New York.

Coulson, R. A., and T. Hernandez. 1983. Alligator Metabolism: Studies on Chemical Reactions in vivo. Pergamon Press, Oxford.

Cox, D. R., AND D. OAKES. 1984. Analysis of Survival Data. Chapman and Hall, London.

Deitz, D. C. 1979. Behavioral Ecology of Young American Alligators. Unpubl. Ph.D. diss., University of Florida, Gainesville.

Deitz, D. C., AND T. C. Hines. 1980. Alligator nesting in north-central Florida. Copeia 1980:249-258.

FERGUSON, M. W. J. 1985. Reproductive biology and embryology of the crocodilians. In C. Gans, F. Billett, and P. Maderson (eds.), Biology of the Reptilia. Vol. 14, pp. 329-421. John Wiley and Sons, New York.

Goodwin, T. M., AND W. R. MARION. 1979. Seasonal activity ranges and habitat preferences of adult alligators in a north-central Florida lake. Journal of Herpetology 13:157-164.

Guillette Jr., L. J., T. S. Gross, G. R. Masson, J. M. Matter, H. F. Percival, and A. R. Woodward. 1994. Developmental abnormalities of the gonad and abnormal sex hormone concentrations in juvenile alligators from contaminated and control lakes in Florida. Environmental Health Perspectives 102: 680-688.

Jennings, M. L., H. F. Percival, And A. R. Woodward. 1988. Evaluation of alligator hatchling and egg removal from 3 Florida lakes. Proceedings of the Annual Conference Southeastern Association of Fish and Wildlife Agencies 42:283-294.

JoAnEN, T. 1969. Nesting ecology of alligators in Louisiana. Proceedings of the Annual Conference Southeastern Association of Game and Fish Commissioners 23:141-151.

Joanen, T., And L. McNease. 1970. A telemetric study of nesting female alligators on Rockefeller Refuge, Louisiana. Proceedings of the Annual Conference Southeastern Association of Game and Fish Commissioners 24:175-193. 
Joanen, T., L. McNease, and M. W. J. Ferguson. 1987. The effects of egg incubation temperature on posthatchling growth of American alligators. In G. J. W. Webb, S. C. Manolis, and P. J. Whitehead (eds.), Wildlife Management: Crocodiles and Alligators, pp. 533-537. Surrey Beatty and Sons, Chipping Norton, New South Wales, Australia.

Kalbfleisch, J. D., and R. L. Prentice. 1980. The Statistical Analysis of Failure Time Data. John Wiley and Sons, Inc., New York.

Kushlan, J. A., AND T. JaCobsen. 1990. Environmental variability and the reproductive success of Everglades alligators. Journal of Herpetology 24:176184.

Kushlan, J. A., AND M. S. Kushlan. 1980. Function of nest attendance in the American alligator. Herpetologica 36:27-32.

Kushlan, J. A., AND J. C. SimON. 1981. Egg manipulation by the American Alligator. Journal of Herpetology 15:451-454.

Littell, R. C., G. A. Milliken, W. W. Stroup, and R. D. WOLFINGER. 1996. SAS System for Mixed Models. SAS Institute Cary, NC.

Rice, K. G., H. F. Percival, A. R. Woodward, and M. L. JENNINGs. 1999. Effects of egg and hatchling harvest on American Alligators in Florida. Journal of Wildlife Management 63:1193-1200.

Seber, G. A. F. 1977. Linear Regression Analysis. John Wiley and Sons, New York.

TAYLOR, D. 1984. Management implications of an adult female alligator telemetry study. Proceedings of the Annual Conference Southeastern Association of Fish and Wildlife Agencies 38:222-227.

Temsiripong, Y. 1999. Growth and Survival of Wild and Repatriated Hatchling American Alligators (Alligator mississippiensis) in Central Florida Lakes. Unpubl. master's thesis, University of Florida, Gainesville.

TuKeY, J. W. 1977. Exploratory Data Analysis. Addison-Wesley, Reading, MA.

Woodward, A. R., T. C. Hines, C. L. Abercrombie, and J. D. Nichols. 1987. Survival of young American alligators on a Florida lake. Journal of Wildlife Management 51:931-937.

Woodward, A. R., H. F. Percival, M. L. Jennings, and C. L. Moore. 1993. Low clutch viability of American Alligators on Lake Apopka. Florida Scientist 56:52-63.

Accepted: 19 June 2006.

Journal of Herpetology, Vol. 40, No. 4, pp. 423-428, 2006

Copyright 2006 Society for the Study of Amphibians and Reptiles

\title{
Habitat Use and Activity of Prairie Kingsnakes (Lampropeltis calligaster calligaster) in Illinois
}

\author{
Matthew L. Richardson, ${ }^{1}$ Patrick J. Weatherhead, and Jefrrey D. Brawn \\ Department of Natural Resources and Environmental Sciences, University of Illinois, 606 East Healey Street, Champaign, \\ Illinois 61820 USA
}

\begin{abstract}
The natural history of Prairie Kingsnakes (Lampropeltis calligaster calligaster) is largely unknown because of their secretive nature. We radio-tracked 10 adult Prairie Kingsnakes (six males, four females) for one complete active season to determine activity patterns and habitat use in an area in Illinois that included forest, grassland, agricultural fields, and roads. The active season extended from approximately April to mid-October. Home ranges of males averaged over four times larger than those of females and usually included the individual's hibernation site. Males and females had similar activity levels throughout the season, with no differences in frequency of movement or distance traveled per move. Snakes were underground at least $\mathbf{7 3 \%}$ of the 574 times they were relocated, suggesting most activity is nocturnal. Collectively, kingsnakes completely avoided agricultural fields and showed a preference for grasslands, but females were strongly associated with grassland edges along roads. This association with roadside edges, and failure of Prairie Kingsnakes to cross roads, suggests that roads may be barriers to movement-an observation consistent with recent evidence that roads can be barriers to movement, negatively affecting snakes in ways other than via direct mortality.
\end{abstract}

Many North American snake populations are declining because of habitat loss (Dodd, 1987; Greene, 1997). In the Midwestern United States, natural habitat has largely been replaced by agriculture, which is generally unsuitable for snakes (Durner and Gates, 1993; Keller and

\footnotetext{
${ }^{1}$ Corresponding Author. Present address: Program in Ecology and Evolutionary Biology, University of Illinois, 505 South Goodwin Avenue, Urbana, Illinois 61801, USA; mlrichar@uiuc.edu
} 